\title{
Chanarin-Dorfman syndrome
}

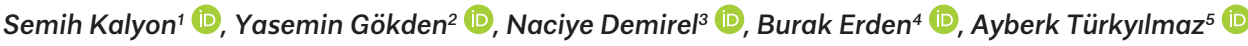 \\ ${ }^{1}$ Department of Internal Medicine, Health Sciences University Okmeydanı Training and Research Hospital, Istanbul, Turkey \\ 2Department of Gastroenterology, Health Sciences University Okmeydanı Training and Research Hospital, Istanbul, Turkey \\ ${ }^{3}$ Department of Hematology, Health Sciences University Okmeydanı Training and Research Hospital, Istanbul, Turkey \\ ${ }^{4}$ Department of Ophthalmology, Health Sciences University Okmeydanı Training and Research Hospital, Istanbul, Turkey \\ ${ }^{5}$ Department of Medical Genetics, Marmara University School of Medicine, Istanbul, Turkey
}

Cite this article as: Kalyon S, Gökden Y, Demirel N, Erden B, Türkyılmaz A. Chanarin-Dorfman syndrome. Turk J Gastroenterol 2019; 30 : 105-8.

\begin{abstract}
Chanarin Dorfman syndrome is a multisystem, very rare, autosomal recessive lipid storage disorder, characterized by the accumulation of lipid vacuoles in neutrophils, and was first described by Dorfman in 1974. Due to a mutation in the ABHD5 gene of the short arm of chromosome 3, lipid is stored in the granulocytes at various sites in the human body, such as the muscle, liver, eye, ear, central nervous system, and bone marrow. Clinically, the disease is presented with ichthyosis, hearing loss, hepatomegaly, splenomegaly, cirrhosis, cataract, keratopathy, myopathy, and mental retardation. A 38-year-old male patient was referred to our Internal Medicine Clinic for consultation with laboratory findings as follows: high aspartate aminotransferase (AST; $203 \mathrm{U} / \mathrm{L}$ ), alanine aminotransferase (ALT; 151 $\mathrm{U} / \mathrm{L})$, gamma-glutamyl transferase (GGT; $167 \mathrm{U} / \mathrm{L})$, creatine kinase (CK; $1127 \mathrm{U} / \mathrm{L})$ levels and low platelet levels (108000). After ultrasonography and gastroscopy, the patient was diagnosed with liver cirrhosis. Bilateral mixed-type hearing loss on audial tests and bilateral punctuate keratopathy, ectropion, and cataract in the left eye on ophthalmological tests were found. For the definitive diagnosis of Chanarin Dorfman syndrome, peripheral blood was examined, which revealed lipid accumulation in the neutrophils (Jordan's anomaly). We emphasize that if a patient has unusual findings, such as ichthyosis, hearing loss, hepatomegaly, splenomegaly, cirrhosis, cataract, keratopathy, myopathy, and mental retardation, the possibility of Chanarin Dorfman syndrome should be considered.

Keywords: Ichthyosis, fibrosis, cataract, ectropion, hearing loss, lipid droplets
\end{abstract}

\section{INTRODUCTION}

Chanarin-Dorfman syndrome is a multisystem, autosomal recessive lipid storage disorder, characterized by the accumulation of lipid vacuoles in neutrophils, and was first described by Dorfman in 1974. Due to the mutation in the ABHD5 gene of the short arm of chromosome 3, lipid is stored in granulocytes at various sites, such as the muscle, liver, eye, ear, central nervous system, and bone marrow. Here, a case with ichthyosis, liver cirrhosis, cataract, keratopathy, ectropion, elevated muscle enzyme levels, minimal loss of hearing, and lipid storage in peripheral blood neutrophils is presented (1-4).

\section{CASE PRESENTATION}

A 38-year-old male patient who has been followed since childhood due to ichthyosis at a dermatology clinic was sent to the Internal Medicine Clinic for consultation with laboratory findings of elevated aspartate aminotransferase (AST; 203 U/L), alanine aminotransferase (ALT; $151 \mathrm{U} / \mathrm{L})$, gamma-glutamyl transferase (GGT; 167 $\mathrm{U} / \mathrm{L})$, and creatine kinase (CK; $1127 \mathrm{U} / \mathrm{L}$ ) levels (Figures 1-3). Additional test results, including partial thrombo- plastin time, activated partial thromboplastin time, and International Normalized Ratio, were within normal limits, except low platelet levels (108000). On ultrasound examination, the liver was found atrophic with irregular edges and had high parenchymal echogenicity and course granular appearance, and the spleen was $18-\mathrm{cm}$ larger. Gastroscopy revealed esophageal varices, and the case was diagnosed as liver cirrhosis. Results of serological assay for viral hepatitis and autoimmune markers for the etiology of cirrhosis were negative. As the concomitance of ichthyosis, liver cirrhosis, and elevated muscle enzyme levels were suspicious of a syndrome, the patient was referred for eye and ear examinations. In audial tests, bilateral mixed-type hearing loss and in ophthalmological examinations, bilateral punctuate keratopathy, ectropion, and cataract formation in the left eye were found. Keratitis ichthyosis deafness syndrome and Chanarin Dorfman syndrome were considered for differential diagnosis. Keratitis ichthyosis deafness syndrome was excluded after genetic investigation. For the diagnosis of Chanarin Dorfman syndrome, peripheral blood was examined, which revealed lipid accumulation

Corresponding Author: Semih Kalyon; semihkalyon@hotmail.com

Received: January 31, 2018 Accepted: May 23, 2018 Available online date: November 16, 2018

(C) Copyright 2019 by The Turkish Society of Gastroenterology · Available online at www.turkjgastroenterol.org

DOI: 10.5152/tjg.2018.18014 
in the neutrophils, a pathognomonic finding of this syndrome (Jordan's anomaly; Figure 4). As a result, the case was diagnosed as Chanarin Dorfman syndrome. Due to social restrictions, further genetic testing could not be done to verify the diagnosis.

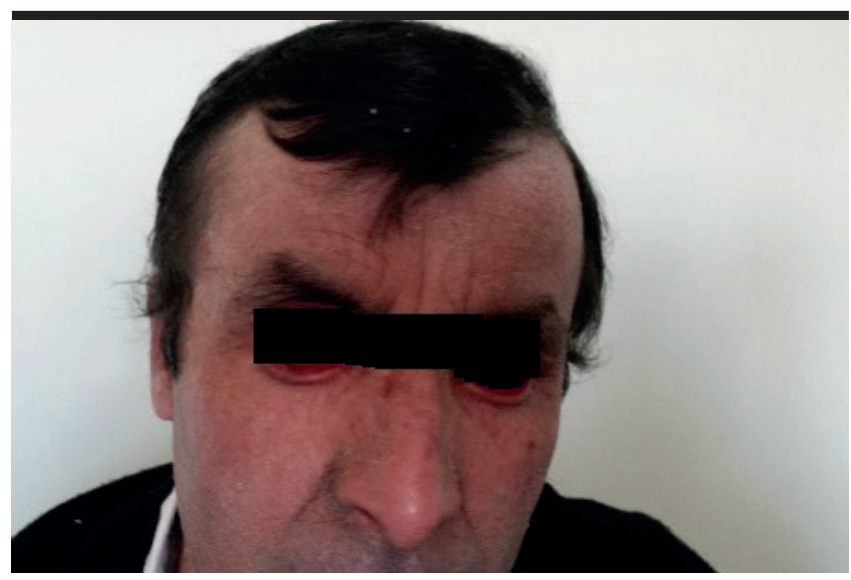

Figure 1. Ichthyosis

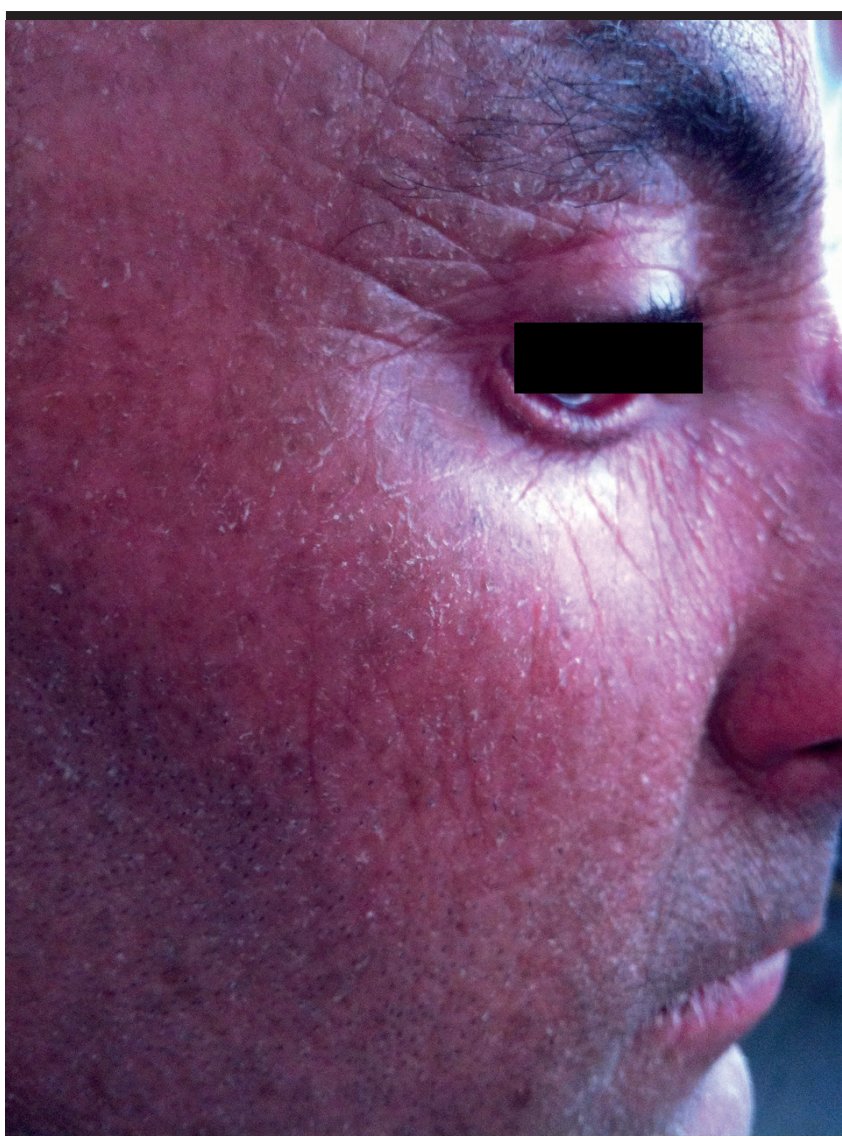

Figure 2. Keratopathy, ectropion, and cataract

\section{DISCUSSION}

Chanarin Dorfman syndrome is a very rare disorder, with a literature search until 2015 including only $<100$ cases (5). The autosomal recessive syndrome developing due to $\mathrm{ABHD} 5 / \mathrm{CGl} 58$ gene mutation is more prevalent in the Mediterranean and Middle East countries (6).

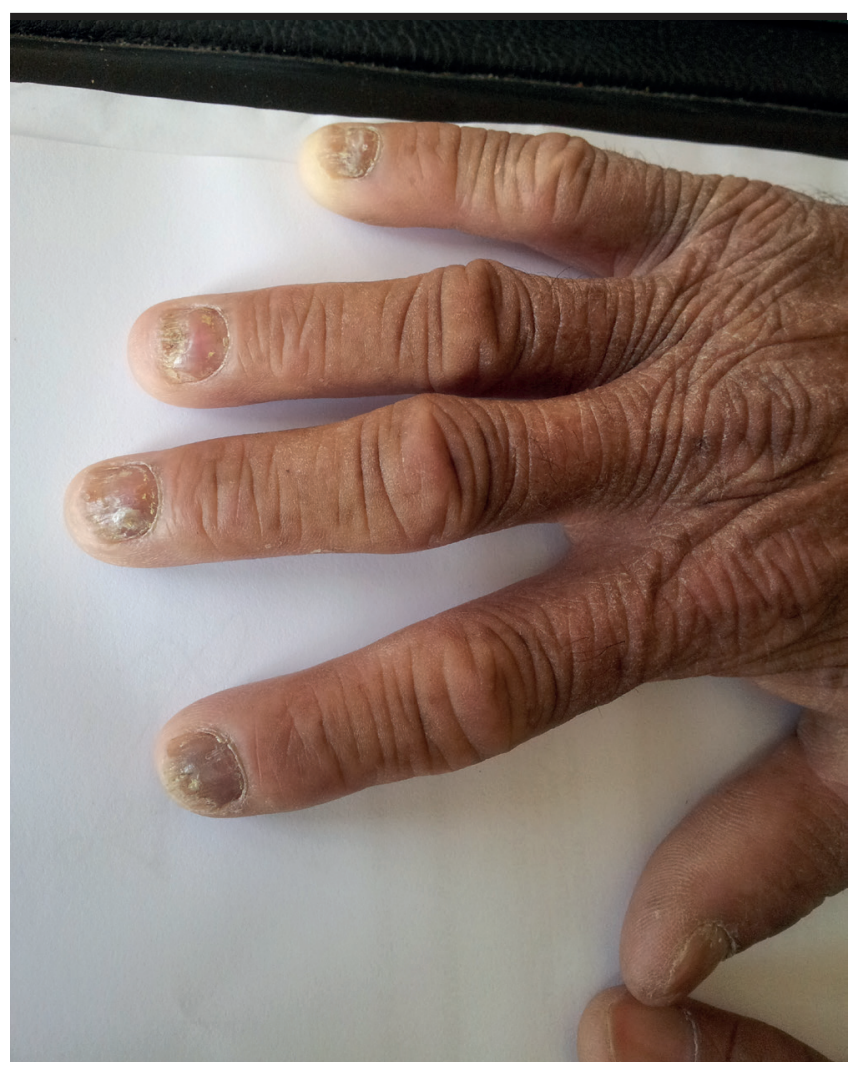

Figure 3. Ichthyosis

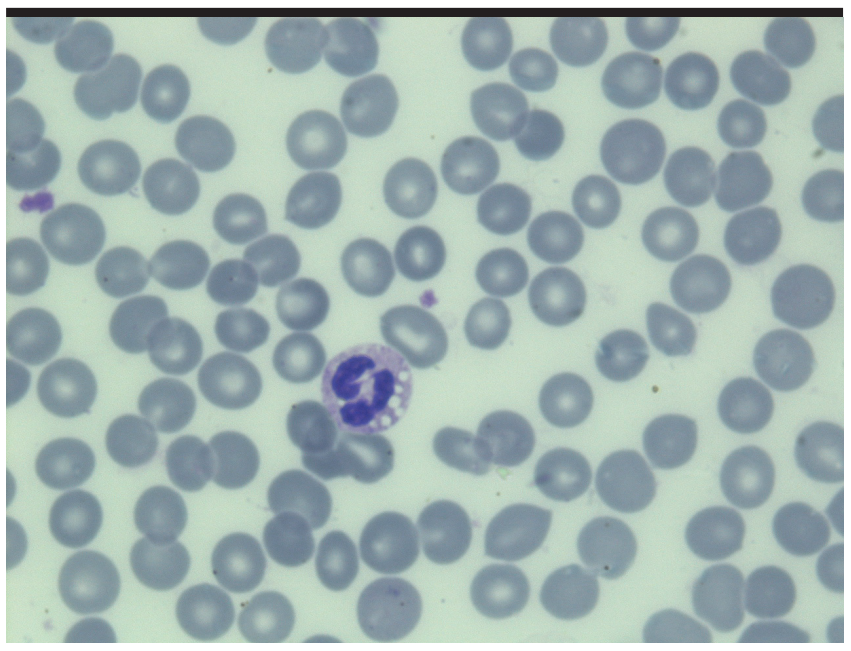

Figure 4. Lipid accumulation in the neutrophils (Jordan's anomaly) 
Lipid accumulation in various tissues occurs as a result of abnormal catabolism of triacylglycerols. Normally, CGI58 protein found on the surface of cytoplasmic lipid droplets activates lipase and leads to lipolysis. Mutations in the ABHD5/CGI58 gene prevent lipolysis, consequently leading to lipid accumulation in leucocytes, fibroblasts, liver, and muscle cells. Clinically, the disease is presented with ichthyosis, hearing loss, hepatomegaly, splenomegaly, cirrhosis, cataract, myopathy, and mental retardation. (7-10). Skin findings include dryness, erythema, hyperkeratosis, and ichthyosis. Our patient was under treatment for ichthyosis since early childhood.

Although hearing loss has been generally defined as the bilateral neurosensory type in earlier reports, our patient had a bilateral mixed-type minimal hearing loss.

Liver involvement is mostly seen as hepatomegaly, fatty liver, and elevated liver enzyme levels and is rarely accompanied with splenomegaly. In our case, liver cirrhosis with splenomegaly was detected.

Eye involvement has been found as cataract formation in $46 \%$ of reported cases. Besides, nystagmus, strabismus, or ectropion may be present. Our patient had cataract, ectropion, and punctate keratopathy.

Although myopathy can be seen in the form of muscle weakness, cardiomyopathy, or aortic insufficiency, our case showed only elevated creatine kinase levels and no muscle weakness or cardiac pathology.

Regarding central nervous system involvement, ataxia, mental retardation, and microcephaly have been reported; however, our patient had none of these disorders.

Elevated serum lipid levels have been usually detected in some previous reports, however, in our case, total cholesterol and triglyceride levels were found within normal ranges, whereas high-density lipoprotein, low-density lipoprotein, and cholesterol levels were low. In lipid electrophoresis, no abnormality was noted, except low pre-beta lipoprotein level (11).

Additionally, final diagnosis in our case was determined with peripheral blood examination, which revealed lipid vacuoles in neutrophils.

After the diagnosis of Chanarin Dorfman syndrome, a multidisciplinary approach of various specialties, includ- ing internal medicine, dermatology, ophthalmology, nutrition, and gastroenterology, should contribute to the treatment, similar to that in the prediagnostic phase. Diet is especially one of the most important components of therapy. Under the guidance of a dietician, our patient started to have a diet that lacked long-chain fatty acids and was rich in medium-chain fatty acids. Ursodeoxycholic acid (Ursofalk; Ali Raif, Ursactive; Pharmactive) $250 \mathrm{mg} 3 \times 1 /$ day per oral and local therapy for ichthyosis provided additional support. Long-term topical therapy was administered for bilateral punctate keratopathy. Our patient is still under regular follow-up and treatment.

\section{CONCLUSION}

We emphasize that in case of different multisystemic findings, such as ichthyosis, hearing loss, hepatomegaly, splenomegaly, cirrhosis, cataract, keratopathy, myopathy, and mental retardation, physicians should suspect Chanarin Dorfman syndrome.

Informed Consent: Written informed consent was obtained from the patient who participated in this study.

Peer-review: Externally peer-reviewed.

Author Contributions: Concept - S.K.; Design - S.K.; Supervision - S.K.; Resources - S.K.; Data Collection and/or Interpretation S.K., Y.G., N.D., B.E., A.T.; Analysis and/or Interpretation - S.K., Y.G., N.D., B.E., A.T.; Literature Search - S.K., Y.G., N.D., B.E., A.T.; Writing Manuscript - S.K.; Critical Review - S.K.

Conflict of Interest: The authors have no conflict of interest to declare.

Financial Disclosure: The authors declared that this study has received no financial support.

\section{REFERENCES}

1. Özkale Y, Erol I, Canan O, Durdu M. Chanarin Dorfman sendromu: Olgu Sunumu. Cukurova Medical Journal 2015; 40: 614-8. [CrossRef] 2. Arslansoyu Çamlar S, Gençpınar P, Makay B, et al. Chanarin Dorfman syndrome with multi system involvement in two siblings. Turk $J$ Haematol 2013; 30: 72-5. [CrossRef]

3. Wollenberg A, Geiger E, Schaller M, Wolff H. Dorfman-Chanarin syndrome in a Turkish kindred: conductor diagnosis requires analysis of multiple eosinophils. Acta Derm Venereo 2000; 80: 39-43. [CrossRef]

4. Pujol RM, Gilaberte M, Toll A, et al. Erythrokeratoderma variabilis like ichthyosis in Chanarin Dorfman syndromöe. Brit J Dermatol 2005; 153: 838-41. [CrossRef]

5. Nur BG, Gencpınar P, Yuzbasıoglu A, Emre SD, Mihci E. Chanarin-Dorfman syndrome: Genotype-Phenotype Correlation. Eur J Med Genet 2015; 58: 238-42 [CrossRef] 
6. Emre S, Unver N, Evans SE, et al. Molecular analysis of Chanarin Dorfman syndrome patients: Identification of novel mutations in the ABHD5 gene. Eur J Med Genet 2010; 53: 141-4. [CrossRef]

7. Selimoğlu MA, Esrefoğlu M, Gul M, Gungor S, Yıldırım C, Seyhan M. Chanarin Dorfman syndrome: clinical features of a rare lipid metabolism disorder. Pediatr Dermatol 2009; 26: 40-3. [CrossRef]

8. Yamaguchi T, Osumi T. Chanarin Dorfman syndrome:deficiency in CGI58, a lipid droplet bound coactivator of lipase. Biochim Biophsy Acta 2009; 1791: 519-23. [CrossRef]
9. Sztalryd C, Xu G, Dorward H, et al. Perilipin A is essential for the translocation of hormone sensitive lipase during lipolytic activitation. J Cell Biol 2003; 161: 1093-103. [CrossRef]

10. Lass A, Zimmermann R, Haemmerle $G$, et al. Adipose triglyceride lipase mediated lipolysis of cellular fat stores is activated by CGI58 and defective in Chanarin Dorfman syndrome. Cell Metab 2006; 3: 309-19. [CrossRef]

11. Düzovali O, Ikizoğlu G, Turhan AH, Yilgör E. Dorfman Chanarin syndrome: a case with hyperlipidemia. Turk J Pediatr 2006; 48: 263-5. 